\title{
Diagnostic capability of EEG in Alzheimer's Disease Related Dementias
}

\author{
Authors \\ Dr V.S. Pal ${ }^{1}$, Dr Vijay Niranjan ${ }^{2 *}$, Dr Abhay Paliwal ${ }^{3}$, Dr Atar Singh ${ }^{4}$ \\ ${ }^{1}$ Professor, ${ }^{2}$ Associate Professor, ${ }^{3}$ Assistant Professor, ${ }^{4} \mathrm{PG}$ resident \\ *Corresponding Author \\ Dr Vijay Niranjan \\ Department of psychiatry, M.G.M. Medical College Indore (M.P.), India
}

\begin{abstract}
Background: With significant increases in life expectancy the number of person with dementia are also climbing. There is no confirmatory test to diagnose dementia. Doctors diagnose dementia based on a medical history, a physical examination, and the characteristic changes in thinking, day-to-day function and behavior. Certain diagnosis of dementia is only possible after post-mortem exam. Efforts are being made to diagnose these neurodegenerative disorders in the early stages.

Aims \& Objectives: 1) Aim: - To study Diagnosis capability of EEG in dementia.

2) To study EEG changes in different parts of brain by using 32 channels, 24 lead EEG machine.

Material \& Methods: The study was conducted by including patients and healthy elderly controls above age 55 years. Subjects were taken from Dept of psychiatry, MGM Medical College and MYH, Indore fulfilling the inclusion and exclusion criteria. Written informed consent will be taken after explaining the objectives and procedure of study in detail. The EEG of participants has been recorded in Mental Hospital Banganga by using departmental RMS® EEG Systems Maximus version 4.2.54. (C) 2007-2008. Data were entered in excel sheet and analyzed using SPSS Software, appropriate statistical test was applied wherever necessary.

Results: Participants with dementia have slow waves preponderance as compare to control. Conclusion: EEG can be used to differentiate person with dementia with healthy individual.

Keywords: $E E G$, dementia.
\end{abstract}

\section{Introduction}

Dementia refers to a group of disorders caused by the gradual dysfunction and/or death of brain cells. As with the other parts of our body, our brain also degenerate as we get old. In dementia there is decline in both memory and thinking which impairs personal activities of daily living. Dementia has been found in medical texts since antiquity $^{1}$. Most of aged persons eventually develop slowed mental activities and problems with remembering things. However, significant memory loss, confusional state and other changes may occur later and indicates that more brain cells are failing. Dementia in the elderly was called senile dementia or senility, and historically viewed as a normal and inevitable aspect of being old, rather than as a disease caused by some agent ${ }^{2}$. 
As dementia advances it leads to increasingly severe symptoms, such as disorientation, mood and behavior changes; confusion about current events, time and place; suspiciousness over family members, friends and other nearby person (s) such as psychiatrist, physician etc; later on more serious memory loss and further degeneration of neurons leads to behavior changes and difficulty in speaking; and other parts of life such as swallowing and walking ${ }^{3}$.

The use of various techniques such as MRI, PET, SPECT and spinal fluid measuring the concentrations of $\beta$-amyloid and phosphorylated and total tau protein have been shown to be helpful in diagnosing dementia.AD and to separate $\mathrm{AD}$ from other brain disorders causing dementia. Some of these diagnostic tools are very expensive (PET), some are invasive (tapping of spinal fluid), and some need personnel with high expertise to evaluate the findings (MRI) and these methods have mainly been used at academic centers $^{4,5}$.

Thus, there is a need for diagnostic biomarkers that can be applied more widely than PET, MRI and spinal fluid markers. EEG has the potential for being such a biomarker, as it is cheap, noninvasive and simple to use $\mathrm{e}^{6,7}$. Numerous studies have been conducted to deal with EEG changes associated with dementia and to identify the degree of severity of dementia, and some studies support the possibility for EEG to detect dementia in early stages $6,7,8,9,10,11$.

\section{Aims \& Objectives}

1) To study Diagnosis capability of EEG in dementia.

2) To study EEG changes in different parts of brain by using 32 channels, 24 lead EEG machine.

\section{Methodology}

Forty healthy control and forty people with dementia were selected. Detailed physical examination was done to rule out any medical or neurological abnormality. The diagnosis of dementia was made using the ICD -10 DCR.
EEGs were taken on the same day. The International system (IS) 10-20 system was used for electrode placement (with 19 electrodes). Even numbered 2,4,6,8 refer to electrodes placed on the right side of the head, whereas odd numbers $1,3,5,7$ refer to electrodes on the left side of head. Lower the number means electrode placed in more central part of head and the " $z$ " refers to the midline of head. We set low pass filter (Lf) at 1 $\mathrm{Hz}$ and high pass filter (Hf) at $70 \mathrm{~Hz}$, sensitivity $7.5 \mu \mathrm{V} / \mathrm{mm}$, Time base $30 \mathrm{~mm} / \mathrm{second}$, and notch filter at $50 \mathrm{~Hz}$ in all recordings. We took about 20 minutes recording of each participant while resting with eyes comfortably closed and examine each EEG record in its full length. In each record we select 10 seconds of artifacts free page in eyes closed and with the help of our EEG software we plot frequency distribution for them separately. The software depicts only 4 types of frequencies i.e. delta $(0.5 \mathrm{~Hz}$ to $4 \mathrm{~Hz})$, theta $(5 \mathrm{~Hz}$ to $8 \mathrm{~Hz})$, alpha $(9 \mathrm{~Hz}$ to $13 \mathrm{~Hz})$ and beta $(14 \mathrm{~Hz}$ to $30 \mathrm{~Hz})$. The frequency of each channels and combined frequency were placed in excel sheets, they are further divided in right and left half as even numbers of electrodes represent right half of head and odd numbers represent left half. So even numbers channels frequencies are summed together and odd channels frequencies summed together. Thus data for control and dementia participants were prepared in eye closed state.

\section{Results}

Table 1. Description of age of study participants in groups.

\begin{tabular}{|l|c|c|}
\hline Age (in years) & Control group & Dementia group \\
\hline Mean & 62.1250 & 65.4750 \\
\hline Median & 58.0000 & 65.0000 \\
\hline Standard deviation & 5.39795 & 8.62015 \\
\hline Minimum & 55.00 & 55.00 \\
\hline Maximum & 85.00 & 85.00 \\
\hline
\end{tabular}

The mean age of control group was about $62 \pm 5.3$ years and dementia group was $65 \pm 8.6$ years. According to the inclusion criteria minimum age was kept 55 years, maximum age was the 85 years in both groups of participants. 
Table 2. Description of gender-wise distribution of study participants in three groups.

\begin{tabular}{|c|c|c|c|c|}
\hline & \multicolumn{2}{|c|}{ Gender } & \multirow[t]{2}{*}{ Total } \\
\hline & & Male & Female & \\
\hline \multirow[t]{2}{*}{ Group } & Control & 27 & 13 & 40 \\
\hline & Dementia & 26 & 14 & 40 \\
\hline
\end{tabular}

The number of male participants was more in both groups as compared to female participants.

Table 3. Description of Delta, Theta, Alpha and Beta frequency distribution on right side, left side and combined in eyes closed situation in Control group.

\begin{tabular}{|l|c|c|c|c|c|}
\hline & & $\begin{array}{c}\text { Delta } \\
(\mathbf{n = 4 0})\end{array}$ & $\begin{array}{c}\text { Theta } \\
(\mathbf{n = 4 0})\end{array}$ & $\begin{array}{c}\text { Alpha } \\
(\mathbf{n = 4 0})\end{array}$ & $\begin{array}{c}\text { Beta } \\
(\mathbf{n = 4 0})\end{array}$ \\
\hline \multirow{3}{*}{ Right } & Mean & 24 & 23 & 32 & 21 \\
\cline { 2 - 6 } & Median & 20.5000 & 22.0000 & 32.0000 & 18.0000 \\
\cline { 2 - 6 } & $\begin{array}{c}\text { Standard } \\
\text { deviation }\end{array}$ & 6.94595 & 7.04377 & 8.61539 & 7.42466 \\
\hline \multirow{4}{*}{ Left } & Mean & 24 & 24 & 31 & 21 \\
\cline { 2 - 6 } & Median & 23.0000 & 23.0000 & 31.5000 & 19.0000 \\
\cline { 2 - 6 } & $\begin{array}{c}\text { Standard } \\
\text { deviation }\end{array}$ & 7.15685 & 5.84802 & 9.85211 & 7.37351 \\
\hline Combined & Mean & 24 & 23 & 33 & 20 \\
\cline { 2 - 6 } & Median & 23.0000 & 21.0000 & 34.0000 & 17.5000 \\
\cline { 2 - 6 } & $\begin{array}{c}\text { Standard } \\
\text { deviation }\end{array}$ & 6.80328 & 6.10989 & 10.95489 & 7.90711 \\
\hline
\end{tabular}

On recording the activity of right side of the brain in control group with eyes closed, it was found that the alpha waves constitute the maximum nearly $32 \%$ of the EEG wave and Beta waves constitutes the least average $21 \%$. The median percentage contribution of Alpha and Beta waves was $32 \%$ and $18 \%$.

EEG of the left side of the brain also showed that the alpha waves constitute the maximum median $31.5 \%$ of the EEG wave and Beta waves constitute the least median $19 \%$.

On recording the EEG activity of whole brain, the similar finding as above was observed i.e. alpha wave constituting the maximum and beta wave constituting the minimum (34\% and $17.5 \%$ respectively) of EEG.
Table 4. Description of Delta, Theta, Alpha and Beta frequency distribution on right side, left side and combined in eyes closed situation in dementia group.

\begin{tabular}{|l|l|l|l|l|l|}
\hline \multirow{2}{*}{ Right } & & $\begin{array}{c}\text { Delta } \\
(\mathbf{n = 4 0})\end{array}$ & $\begin{array}{c}\text { Theta } \\
(\mathbf{n = 4 0})\end{array}$ & $\begin{array}{c}\text { Alpha } \\
(\mathbf{n = 4 0})\end{array}$ & $\begin{array}{c}\text { Beta } \\
(\mathbf{n}=\mathbf{4 0})\end{array}$ \\
\cline { 2 - 6 } & Mean & 40.5500 & 28.0500 & 16.2250 & 14.8500 \\
\cline { 2 - 6 } & Median & 36.5000 & 26.0000 & 16.0000 & 15.0000 \\
\hline \multirow{2}{*}{ Left } & $\begin{array}{l}\text { Standard } \\
\text { deviation }\end{array}$ & 10.42175 & 6.67160 & 4.64917 & 5.82457 \\
\cline { 2 - 6 } & Mean & 40.3250 & 28.2500 & 16.3500 & 14.8750 \\
\cline { 2 - 6 } & Median & 41.5000 & 28.0000 & 16.0000 & 15.0000 \\
\cline { 2 - 6 } & $\begin{array}{l}\text { Standard } \\
\text { deviation }\end{array}$ & 9.28298 & 5.21217 & 4.94871 & 5.30209 \\
\cline { 2 - 6 } & Mean & 44.4000 & 27.2250 & 15.0250 & 13.3750 \\
\cline { 2 - 6 } & Median & 42.0000 & 26.0000 & 15.0000 & 13.5000 \\
\cline { 2 - 6 } & $\begin{array}{l}\text { Standard } \\
\text { deviation }\end{array}$ & 11.45963 & 6.61191 & 5.07628 & 5.07223 \\
\hline
\end{tabular}

Unlike control group the EEG of right side of brain on eyes closed condition in dementia patients showed that the maximum proportion is of Delta wave, however Beta waves remained minimum. Left side of the brain also showed the same pattern.

The combined findings were also similar. Majority contribution were from slower waves i.e. delta and theta $(71.6 \%)$ which was significantly higher from control group (47\%).

Table 5 Comparison of combined Delta, Theta, Alpha and Beta frequency distribution with eyes closed between control group and dementia group.

\begin{tabular}{|l|c|c|c|c|c|}
\hline \multirow{2}{*}{} & \multicolumn{2}{|c|}{ Control group } & \multicolumn{2}{c|}{ Dementia group } & \multirow{2}{*}{ p value } \\
\cline { 2 - 5 } & $\begin{array}{c}\text { Mean } \\
\text { rank }\end{array}$ & Median & $\begin{array}{c}\text { Mean } \\
\text { rank }\end{array}$ & Median & \\
\hline Delta & 38.40 & 23.00 & 93.29 & 42.0000 & $0.000^{*}$ \\
\hline Theta & 39.16 & 21.00 & 59.84 & 26.0000 & $0.000^{*}$ \\
\hline Alpha & 89.95 & 34.00 & 32.10 & 15.0000 & $0.000^{*}$ \\
\hline Beta & 77.25 & 17.50 & 47.21 & 13.5000 & $0.000^{*}$ \\
\hline
\end{tabular}

The combined EEG Findings in eyes closed situation revealed a significant difference between the proportions of delta wave in EEG amongst different groups. Significant difference was also observed between the median percent contributed by theta wave in the EEG of three groups. The similar were the findings with respect to alpha waves and beta wave.

\section{Discussion}

This was a cross sectional hospital based study to compare the frequency distribution among healthy 
control and their respective age and sex matched diseased participants.

The mean age of control group was about $62 \pm 5$ years and dementia group was $65 \pm 8$ years in our study. While the mean ages in other studies were $74 \pm 9$ and $52 \pm 14$ years for $\mathrm{AD}$ and $\mathrm{NC}$, respectively ${ }^{8} ; 71.7 \pm 8$ years of patient group and $66.5 \pm 7$ years for $\mathrm{NC}^{9}$. In most of studies control group have less age as compared to patient group as in our study ${ }^{6,8,9}$. The male participants were outnumbered as comparison to women, in all 80 participant female were only 27 (33.75\%), contrast to our study Knut Engedal et al (2015) have $57 \%$ female participants and Emanuel et al (2015) have $49 \%$ female participants. As life expectancy for women is higher than men and age is major risk factor for dementia, so incidence of dementia is higher in women ${ }^{12,13}$ whereas some showed no sex difference in incidence for dementia $^{14}$, while Matthews et al 2016 showed increased incidences in men as compared to women ${ }^{15}$.

We found more male participants in both groups as compared to female the reason behind age and sex disparity between our study and other studies may be sociocultural ${ }^{16}$.

Many studies have demonstrated association between dementia and EEG changes ${ }^{7,8,9,10,11}$. In our study control group eyes closed EEG recording showed maximum alpha and minimum beta waves, constituting $(34 \%$ and $17.5 \%$ respectively). Unlike control group the EEG of dementia group eyes closed showed that the maximum proportion is of Delta wave (44\%) and minimum proportion remain to be of Beta wave $(27 \%)$. In dementia group majority of contribution were from slower waves i.e. delta and theta (71.6\%) which was significantly higher from control group.

\section{Conclusion}

Cognitive decline was associated with appearance of slow waves. In contrast, no alterations were found in healthy controls. Normal EEG recordings with preserved alpha and beta waves rule out the possibility of having dementia. Thus EEG recording can serve as a potential marker for dementia.

\section{Recommendation}

EEG study should be advised if clear clinical indications are present. EEG study can also help the patient or family to understand the ongoing disease process. EEG may also differentiate between a generalized and a focal abnormality, and guide the clinician to further appropriate imaging studies. EEG can be used important diagnostic tool in different dementias in which specific morphologic lesions are not apparent on imaging studies.

\section{Limitation of the study}

1) Severely demented patients have difficulty in understanding instructions during EEG recording leads to poor EEG recording hence not included in study.

2) Some participant refused to undergo EEG recording because of fear of close space.

3) Specific dementia types were not included and they were all summed into dementia group.

4) Severity of dementia not assessed.

\section{References}

1. Berchtold, N.C. and Cotman, C.W. (1998): Evolution in the conceptu-alization of dementia and Alzheimer's disease: GrecoRoman period to the 1960s. Neurobiol Aging 19, 173-189

2. Katzman R (April 1976). "Editorial: The prevalence and malignancy of Alzheimer disease. A major killer". Archives of Neurology. 33 (4): 217-18.

3. Alva G, Potkin SG (2003): Alzheimer disease and other dementias. Clin Geriatr Med; 19(4):763-776

4. Korf ES, Wahlund LO, Visser PJ, Scheltens P (2004): Medial temporal lobe atrophy on MRI predicts dementia in 
patients with mild cognitive impairment. Neurology 63: 94-100.

5. Mosconi L, Mistur R, Switalski R, Tsui WH, Glodzik L, Li Y, Pirraglia E, De Santi S, Reisberg B, Wisniewski T, de Leon MJ (2009): FDG-PET changes in brain glucose metabolism from normal cognition to pathologically verified Alzheimer's disease. Eur J Nucl Med Mol Imaging; 36: 811-822.

6. Claus JJ, Strijers RL, Jonkman EJ, (1999). The diagnostic value of electroencephalography in mild senile Alzheimer's disease. Clin Neurophysiol; 110:825-832.

7. Steven Michael Snyder, James Richard Hall, Sonya Lynn Cornwell, James David Falk,(2011) Addition of EEG improves accuracy of a logistic model that uses neuropsychological and cardiovascular factors to identify dementia and MCI, Psychiatry Research,186 (1) 97-102.

8. Gearing M, Mirra S S,Hedreen J C,SumiS M, Hansen L A, Heyman A (1995). The consortium to establish a registry for Alzheimer's disease(CERAD).Part X. Neuropathology confirmation of the clinical diagnosis of Alzheimer's disease. Neurology 45(3)461-6.

9. Dubois M F, Hebert R (2001): The incidence of vascular dementia in Canada: a comparison with Europe and East Asia. Neuroepidemiology 20(3):179-87.

10. Moretti, Davide \& Zanetti, Orazio \& Binetti, Giuliano \& Frisoni, Giovanni. (2012). Quantitative EEG Markers in Mild Cognitive Impairment: Degenerative versus Vascular Brain Impairment. International journal of Alzheimer's disease. (7) 75-7.
11. Hennie Lee and Geert J F Brekelmans and Gerwin Roks (2015) The EEG as a diagnostic tool in distinguishing between dementia with Lewy bodies and Alzheimer's disease, Clinical Neurophysiology, 126,1735-1739.

12. Fratiglioni L, Viitanen M, von Strauss E (1997). Very old women at highest risk of dementia and Alzheimer disease: incidence data from the Kungsholmen Project, Stockholm. Neurol ;48:132-138.

13. Letenneur L, Gilleron V, Commenges (1999). Are sex and educational level independent predictors of dementia and Alzheimer's disease? Incidence data from the PAQUID project. J Neurol Neurosurg Psychiatry. 66:177-183.

14. Edland SD, Rocca WA, Petersen RC (2002): Dementia and Alzheimer disease incidence rates do not vary by sex in Rochester, MN. Arch Neurol. 59:15891593

15. Matthews FE, Stephan BC, Robinson L (2016). A two-decade dementia incidence comparison from the Cognitive Function and Ageing Studies I and II. Nat Commun. 7:11398.

16. Sayegh, P., \& Knight, B. G. (2013). Crosscultural differences in dementia: the Sociocultural Health Belief Model. International Psychogeriatrics, 25(4), 517530. 